\title{
A review on tramadol toxicity: mechanism of action, clinical presentation, and treatment
}

\author{
Samaneh Nakhaee ${ }^{1} \cdot$ Christopher Hoyte $^{2,3} \cdot$ Richard C. Dart $^{3} \cdot$ Masoumeh Askari $^{1} \cdot$ Roland J. Lamarine $^{4}$. \\ Omid Mehrpour ${ }^{1,5}$
}

Received: 23 August 2020 / Accepted: 24 December 2020 / Published online: 24 March 2021

(c) The Author(s) 2021

\begin{abstract}
Aims As an analgesic that acts upon the central nervous system (CNS), tramadol has gained popularity in treating moderate to severe pain. Recently, it has been increasingly reported as a drug of misuse with intentional overdoses or intoxications. This review focuses on tramadol intoxication in humans and its effects on different systems.

Subject and method This narrative review provides a comprehensive view of the pharmacokinetics, mechanism of action, and incidence of tramadol toxicity with an in-depth look at its side effects. In addition, the main approaches to the management of tramadol poisoning are described.

Results Tramadol poisoning can affect multiple organ systems: gastrointestinal, central nervous system (seizure, CNS depression, low-grade coma, anxiety, and over time anoxic brain damage), cardiovascular system (palpitation, mild hypertension to life-threatening complications such as cardiopulmonary arrest), respiratory system, renal system (renal failure with higher doses of tramadol intoxication), musculoskeletal system (rhabdomyolysis), endocrine system (hypoglycemia), as well as, cause serotonin syndrome. Seizure, a serious nervous disturbance, is more common in tramadol intoxication than with other opioids. Fatal tramadol intoxications are uncommon, except in ingestion cases concurrent with other medications, particularly CNS depressants, most commonly benzodiazepines, and ethanol.

Conclusion With the increasing popularity of tramadol, physicians must be aware of its adverse effects, substantial abuse potential, and drug interactions, to weigh its risk-benefit ratio for pain management. Alternative therapies might be considered in patients with a previous overdose history to reduce risks for adverse outcomes.
\end{abstract}

Keywords Tramadol $\cdot$ Intoxication $\cdot$ Poisoning $\cdot$ Toxicity $\cdot$ Overdose

Omid Mehrpour

omid.mehrpour@yahoo.com.au

1 Medical Toxicology and Drug Abuse Research Center (MTDRC), Birjand University of Medical Sciences (BUMS), Birjand, Iran

2 University of Colorado Anschutz Medical Campus, Aurora, CO, USA

3 Arizona Poison and Drug Information Center, The University of Arizona, College of Pharmacy, Tucson, AZ, USA

4 Department of Public Health, California State University Chico, Chico, CA, USA

5 Mel and Enid Zuckerman, College of Public Health, University of Arizona, Tucson, AZ, USA

\section{Introduction}

Tramadol is one of the most commonly prescribed central nervous system (CNS) analgesics used globally. It is widely prescribed for the treatment of moderate to severe pain [1]. It is one of the most widely prescribed opioids in many countries [2-4]. Because of an increased incidence of tramadolrelated overdoses and deaths in the last decade, it has been classified as a controlled substance in several countries [4]. It was thought that tramadol had a lower risk for overdose, constipation, and addiction than other opioids, but some studies propose that phenotypic differences can contribute to its analgesic and side effect profile [5].

The International Narcotics Control Board review of 2013, revealed that tramadol abuse was problematic for several countries (32 out of 77 countries responding) [6]. However, recent studies have increasingly reported tramadol as 
a drug of misuse with intentional overdoses or intoxications [3, 4, 7-10]. While much is known about tramadol's efficacy for pain, there is increasing evidence from post-marketing surveillance indicating significant side effects. In 2004, the Australian Adverse Drug Reactions Advisory Committee received several adverse events due solely to tramadol use. These reactions suggest that the decision to prescribe tramadol should be carefully considered [11]. Tramadol is responsible for severe intoxications leading to consciousness disorder (30\%), seizures (15\%), agitation (10\%), and respiratory depression (5\%) [12]. Easy availability of prescription opioids in some countries may be contributing to increased drug-related health problems, hospitalizations, and mortality [8]. This review focuses on a variety of aspects of tramadol intoxication in humans and its effects on different systems.

\section{Methods}

In this review, several databanks, including PubMed, Web of Science, Scopus, Embase, and Google Scholar were searched using MESH headings and a combination of relevant keywords including tramadol, poisoning, intoxication, and overdose. Two researchers independently searched the databases mentioned above until 30 May 2020. No limitations were considered in the year or language of studies. Papers published in English or having an abstract in English were included. Titles and abstracts of retrieved articles were initially examined by two reviewers independently (O.M and S.N). The literature search was explicitly targeted toward studies focusing on tramadol's side effects on different body systems.

Case-control, cohort, cross-sectional, animal studies, and case reports were assessed. To find additional relevant articles, reference lists from the identified studies were also examined. The screening was performed after exclusion of duplications. Moreover, articles with inadequate data pertaining to the study objectives, as well as editorials, and conference papers, were excluded. Of the citations retrieved, one hundred eighteen studies were included in this narrative review. Papers 11, 13, 38, and 56 included original studies on humans, case reports, animal studies, and reviews, respectively.

\section{Results}

\section{Incidence}

An abuse rate of 69 per thousand persons per year has been reported for tramadol, with a dependence rate of $10 \%$ among the abusers [13]. Young male adults were more frequently involved in tramadol abuse and intoxication than females.
Moreover, the most common route of poisoning was oral (>98\%), which is consistent with the most commonly available form of tramadol [2, 3, 7].

Suicide attempts have been reported as the most common cause of intoxication (52-80\%), followed by abuse (18-31\%), and unintentional intoxication (1-11\%) [2, 7, 14, 15]. A history of chronic tramadol abuse or opioid dependence was reported in at least $20 \%$ of cases of tramadol poisoning [2, 16-18]. A previous history of suicide attempts, substance abuse, and mental disorders played an important role in intentional intoxications [2, 7]. Previous literature also reported an association of tramadol intoxication with self-induced injuries and borderline personality disorders $[19,20]$.

\section{Tramadol metabolism}

The liver metabolizes tramadol by $N$ - and $O$-demethylation mediated by the cytochrome $\mathrm{P} 450$ pathways (particularly CYP2D6) and is mainly excreted through the kidneys [1]. Therefore, any impairment in these systems or concurrent use of other medications that also are metabolized through the same hepatic pathways may cause overdose or intoxication. Wu et al. studied the metabolism of tramadol and subsequently produced metabolites. They detected 26 metabolites for tramadol due to liver metabolism, consisting of 14 metabolites from phase I of liver metabolism (M1 to M11 and M31 to M33) and 12 metabolites from phase II (7 glucuronides-M12 to 18 - and 5 sulfonates-M19 to 23) [21]. Following oral administration of tramadol, out of 26 metabolites, only 23 metabolites were identified in the urine [21, 22]. At the same time, M31 to M33 were identified only in liver microsomes [21]. Among these 26 metabolites detected in humans, M12, M19 to M23, and M33 were not detected in mice or dogs [22]. Its metabolites result from tramadol metabolism by the liver, of which only $O$-desmethyl tramadol (M1) and $O, N$-di-desmethyl tramadol (M5) are pharmacologically active. M1 is the result of $O$ - demethylation by cytochrome P450 2D6 (CYP2D6)[23].

Selective analysis of tramadol and M1 showed (-)M1 levels were generally higher than (+)-M1 levels [24]. CYP2B6 and CYP3A4 are responsible for the $N$-methylation of tramadol to $N$-desmethyl tramadol (M2) [25]. M1 and M2 may then be broken down into secondary metabolites, $N, N$ didesmethyl tramadol (M3) and $N, O$-didesmethyl tramadol (M5), and then to $\mathrm{N}, \mathrm{N}, \mathrm{O}$-tridesmethyl tramadol (M4) [24]. Following bioactivation in the liver, M1 is released into the bloodstream, enters the central nervous system, and stimulates $\mu$-opioid receptors. In phase II metabolism, M1 is inactivated by glucuronidation in the liver, mostly via UGT2B7 and UGT1A8 [24] (Fig. 1).

Various metabolizer phenotypes (MP) are predictable by genetic variants in CYP2D6. It has been reported that 
Fig. 1 Schematic diagram of tramadol metabolism

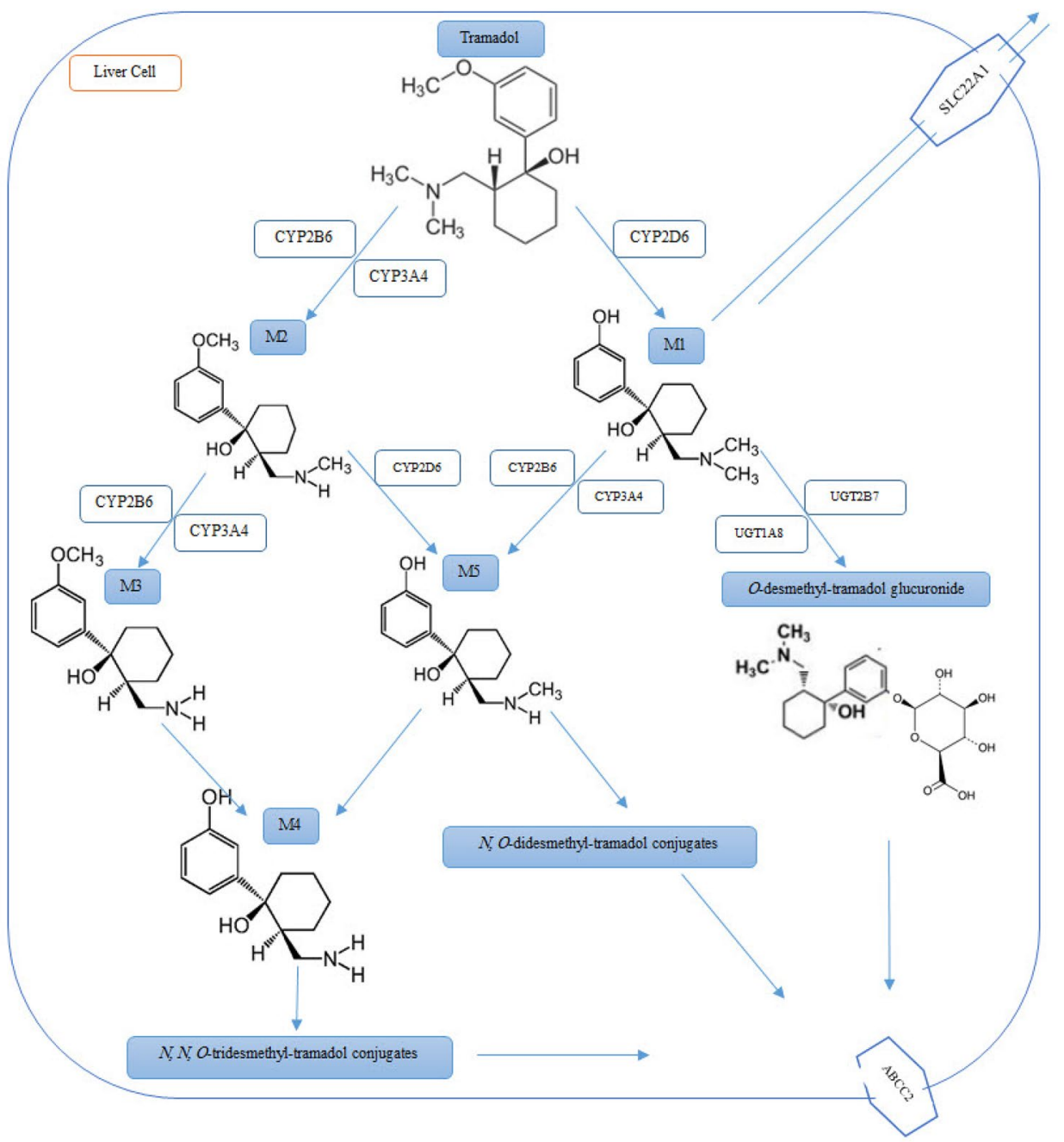

the CYP2D6 genotype affects the plasma levels of tramadol and its metabolites, as well as, tramadol efficacy and adverse drug reactions [26-28]. The CYP2D6 phenotype is classified into different groups based on the metabolizer status, including ultra-rapid metabolizers (UMs), extensive metabolizers (EMs), intermediate metabolizers (IMs), and poor metabolizers (PMs). EMs carry two active CYP2D6 alleles, IMs one inactive and one reduced activity CYP2D6 allele, and PMs two inactive CYP2D6 alleles. A minimum of three active CYP2D6 alleles are carried by UMs [24]. It has been reported that UMs are more prone to experience the side effects of tramadol [29]. PMs may contain higher tramadol concentrations, and the simultaneous use of CYP2D6 or CYP3A4 inhibitors such as fluoxetine, paroxetine and quinidine could cause substantial drug interactions [24]. Genetic polymorphism of CYP2D6 accounts for major inter-individual differences in tramadol metabolism, its peak blood levels, and clinical presentations with therapeutic doses or overdoses [30, 31]. Polymorphic CYP2D6 action has been reported to be determinative of tramadol's pharmacokinetics and pharmacodynamics via hepatic phase I $O$-demethylation of (+)-tramadol to (+)-O-desmethyl tramadol. This could elucidate the broad range of tramadol toxic doses reported in the literature [32]. Individuals with Middle Eastern and African ethnicities are more likely to be UMs in comparison with North American and Middle European people (21-29\% vs. $1-5 \%$, respectively) [33]. Consequently, more sedation, opioid effect, and adverse effects are expected in the former group [34].

An individual's CYP genetics influence the opioid analgesic potency of an administered dose of tramadol. PMs experience small conversions to active M1 opioid metabolites and UMs, experiencing a higher opioid analgesic effect. The importance of CYP metabolism should lead to considering pharmacogenomic tools before the administration of tramadol in clinical centers [5].

Moreover, tramadol is considered as an efficient probe for CYP2D6 phenotyping [35]. Pederson et al. found that $50 \mathrm{mg}$ of tramadol has potential as a CYP2D6 phenotype probe using the 8-h urinary ratio of (-)-M1/(+)-M1 concentrations. In addition, they reported a metabolic ratio of 2.0 or higher for PMs [35]. 


\section{Mechanism of action}

Tramadol has both opioid and non-opioid mechanisms of action. It is an agonist of the opioid (mainly $\mu$-opioid) and gamma-aminobutyric acid (GABA) receptors and inhibits the reuptake of serotonin (SSRI) and norepinephrine (SNRI) [23] (Fig. 2). Tramadol is a racemic mixture of $(+)$ and $(-)$ enantiomers with different affinities for the opioid receptors and various impacts on serotonin and norepinephrine reuptake. Therefore, their ratio may affect the threshold of tramadol therapeutic and toxic effects. Enantiomer $(+)$ is the opioid part, but it also accelerates serotonin release and prevents its reuptake. Enantiomer (-) is considered to be a norepinephrine reuptake inhibitor (SNRI) [2].

Of the identified tramadol metabolites, M1, M2, and M5 are the main ones. Moreover, M1 has a greater inhibitory effect against amine reuptake and is largely responsible for analgesic as well as adverse effects in intoxicated patients $[3,36]$. Overall, analgesic activity is caused by two tramadol enantiomers $([+]$-tramadol and [ -$]$-tramadol), along with metabolite M1 [24]. In-vitro and clinical studies have shown that the metabolite M1 is significantly more potent than tramadol $\mu$-opioid receptors in binding and producing analgesia. At the same time, the parent drug is only a weak $\mu$-opioid receptor agonist [37, 38]. (+)-M1 has a significantly higher affinity for the $\mu$-opioid receptor $(\mathrm{Ki}=0.0034 \mu \mathrm{M})$ than the parent drug $(+/-)$-tramadol $(\mathrm{Ki}=2.4 \mu \mathrm{M})$ as well as $(+/-)-\mathrm{M} 5(\mathrm{Ki}=0.1 \mu \mathrm{M})$ and (-)-M1 $(\mathrm{Ki}=0.24 \mu \mathrm{M})[37,39]$. Thus, tramadol's parent form exhibits about a 700-fold lower affinity than its (+) M1 metabolite. The (+/-)-tramadol also inhibits the reuptake of serotonin neurotransmitters (by binding to transporter hSERT) and norepinephrine (by binding to transporter hNET). The racemic tramadol binds to hNET and hSERT with Ki values at 14.6 and $1.19 \mu \mathrm{M}$, respectively [40] (Table1).

The half-lives of tramadol and M1 are 5-6 h and 7-9 h, respectively $[23,41]$. Therefore, the longer elimination half-life of M1 may instigate bioaccumulation with regular dosing. Additionally, the results of one study showed that tramadol half-life is dose-dependent, which could explain the adverse consequences of severe overdoses [42].

Table 1 Evaluation of inhibitory constant (Ki) of binding activity in tramadol, tramadol enantiomers and metabolites at human MOR, NET, and SERT

\begin{tabular}{llll}
\hline & $\begin{array}{l}\text { MOR Ki bind- } \\
\text { ing affinity } \\
(\mu \mathrm{M})\end{array}$ & $\begin{array}{l}\text { NET Ki bind- } \\
\text { ing affinity } \\
(\mu \mathrm{M})\end{array}$ & $\begin{array}{l}\text { SERT Ki } \\
\text { binding affinity } \\
(\mu \mathrm{M})\end{array}$ \\
\hline Racemic tramadol & 2.4 & 14.6 & 1.19 \\
$(+)$ Tramadol & 1.33 & NA & 0.53 \\
$(-)$ Tramadol & 24.8 & 0.43 & NA \\
Tramadol (+) M1 & 0.0034 & NA & NA \\
Tramadol (-) M1 & 0.24 & NA & NA \\
Tramadol (+/-) & 0.1 & NA & NA \\
M5 & & & \\
\hline
\end{tabular}

MOR $\mu$-opioid receptor, NA not available, NET norepinephrine (noradrenaline) transporter, SERT serotonin transporter
Fig. 2 Potential mechanisms for tramadol induced seizure and serotonin syndrome. $M A O-A$ monoamine oxidase A, GABAA gamma-Aminobutyric acid type A

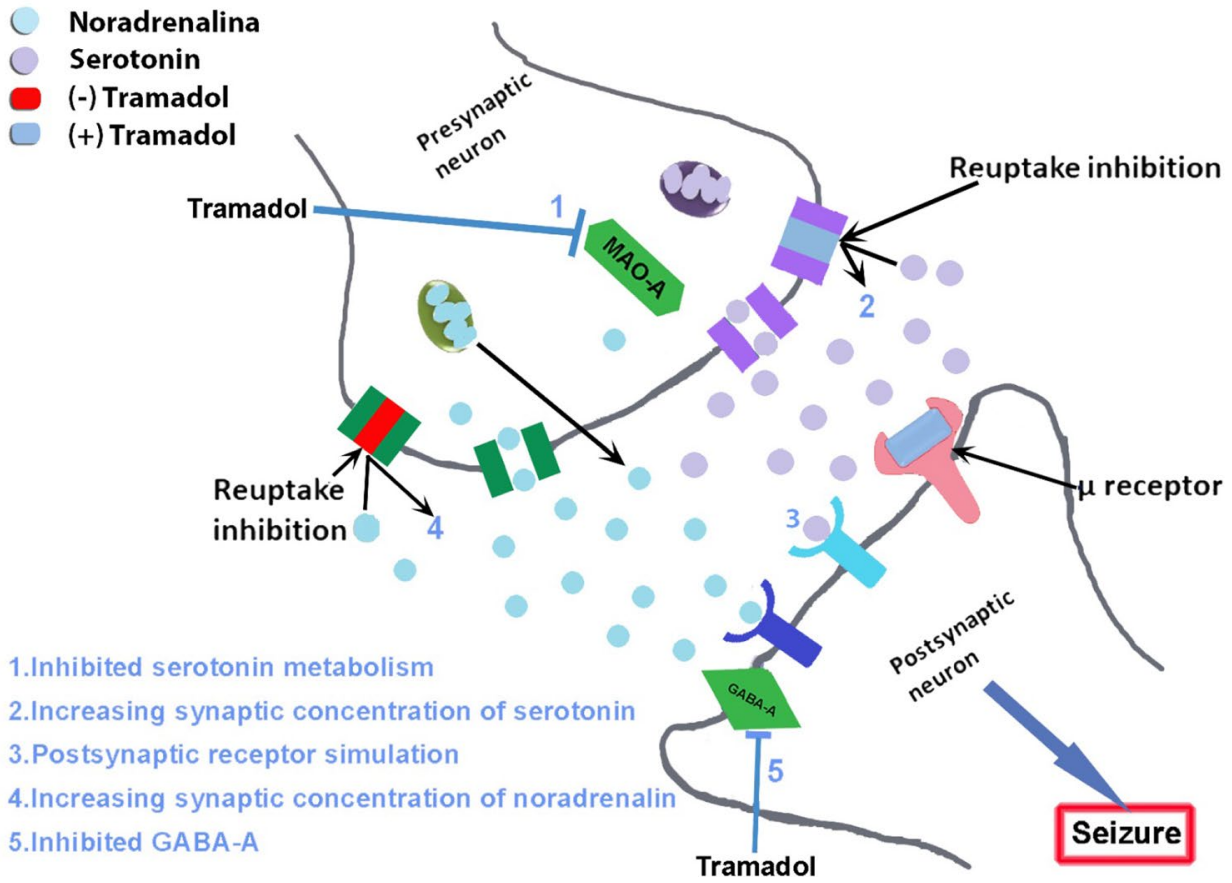




\section{Clinical presentations of tramadol intoxication}

Tramadol is available in different forms with a standard therapeutic dose of $50 \mathrm{mg}$ orally, $100 \mathrm{mg}$ rectally, and 50-100 mg parenterally. The maximum recommended daily dose is $400 \mathrm{mg}$ [23]. It is commonly administered orally, rapidly and almost entirely absorbed, with peak effect reached within $2 \mathrm{~h}$ [43]. The therapeutic blood concentration of tramadol ranges from 0.1 to $0.3 \mathrm{mg} / \mathrm{L}$. Moreover, toxic and possibly lethal blood concentrations have been reported at 1 and $2 \mathrm{mg} / \mathrm{L}$, respectively [32]. Tramadol is disseminated into the spleen, lungs, brain, kidneys, and liver [44]. It can pass through the placental barrier and has been detected in breast milk in small amounts [23]. While the current evidence supports tramadol's efficacy and safety, there is an increasingly large amount of evidence regarding its adverse effects and fatal complications, even in the absence of interacting drugs [45].

The most commonly reported adverse effects are nausea, vomiting, CNS depression, seizure, dizziness, agitation, tachycardia, hypertension, reduced appetite, headache, itching, pruritus and rash, and gastric irritation, and skin eruption [3, 7, 14, 46, 47]. Rapid metabolizers of CYP may experience more adverse reactions (ARs) such as opioid toxidrome effects [5]. However, Pederson et al. found a weak correlation between ARs and the genotype and phenotype. However, they found that females are more susceptible to ARs of tramadol, and they found a slight reduction in CYP2C9, CYP2C19, and/or CYP1A2 activity in four female subjects with ARs of moderate-to-severe intensity such as headache, dizziness, nausea, and vomiting [48]. These observations almost certainly reflect unrecognized pharmacodynamic interactions of tramadol that can be observed despite the single-dose and low doses of the individual drugs. This may be understandable as tramadol has a complex metabolism with many detected metabolites with various effects.

A triad of opiate overdoses (i.e., miosis, respiratory depression, and decreased level of consciousness) can be observed in tramadol intoxication. Unlike opioids, tramadol can lead to hypertension, tremor, irritability, and increased deep tendon reflexes $[7,49]$. Poisoning may also lead to multiple organ failure, coma, cardiopulmonary arrest, and death [45]. In the following section, the adverse effects of tramadol on different systems will be delineated (Fig. 3).

\section{Gastrointestinal system}

Nausea and vomiting have been reported as common presenting symptoms with both therapeutic doses and overdoses $[7,10,11,14,50]$. These symptoms usually resolve within $24 \mathrm{~h}$ with supportive care and early administration of charcoal [51].
Results of an animal trial demonstrated that the main hepatic histopathologic finding with therapeutic doses of tramadol was vacuolization in tubular cells [52]. Although uncommon, acute liver failure following tramadol intoxication has been reported $[4,36]$, which is usually in a setting of multiple organ failure. Management of tramadol-associated liver failure is mainly supportive No evidence is available regarding the uses of molecular absorbent recirculating systems [36]. Hyperamylasemia in a patient with tramadol overdose was likely due to hypoxemia and lactic acidosis [53].

\section{Central nervous system}

CNS symptoms of tramadol poisoning include, but are not limited to, CNS depression, low-grade coma, anxiety, and seizure $[3,7,10,34,54-56]$. Seizure as a serious nervous disturbance is more common in tramadol intoxication than with other opioids $[2,9-11,34,54,55,57-67]$ (Table 2) and the detailed mechanism of tramadol-induced seizure requires further investigation [2]. The incidence of seizure has been reported to be $8-81 \%$ with tramadol overdose [2, $3,7,9-11,14,34,50,54,68,69]$ and it may occur in infants and children, as well $[63,70]$. The pharmacological reasons for such a high seizure risk are unclear; most patients will have a normal EEG and CT scan of the brain $[9,34]$.

Tramadol induced seizures may occur in the first $6 \mathrm{~h}$ after ingestion of tramadol $[2,9,14,64]$. Seizures are typically of the tonic-clonic type [2, 7, 9, 34], single [2, 10, 59], and occur at doses as low as 50-100 mg [9, 66, 71]. Although controversial, it seems that tramadol-induced seizures are dose-dependent; however, a seizure may occur with its therapeutic use, abuse, or overdose $[2,9,14,66]$. They have been reported more frequently in higher doses $[2,3,7,23,61$, 67]; therefore, higher doses of tramadol could be considered a risk factor $[67,72]$. Patients with recurrent seizures ingested, on average double the tramadol dose of single seizure patients [10]. In contrast, some studies reported a non-significant difference of serum tramadol concentrations between patients with seizures and those without seizures $[2,17,73,74]$.

The seizure risk is most significant in those with an existing seizure disorder or a history of previous seizures $[2,4,66]$. In addition, the highest seizure rate $(54.4 \%)$ has been reported in patients with a history of tramadol abuse or intoxication, as well as, in chronic tramadol users (44\%) [34]. Tramadol may also increase the seizure risk with concurrent use of serotonergic medications [1].

There is controversy about the effect of benzodiazepines (BZD) and naloxone in tramadol-related seizures. Some studies found a decreased risk of seizure in patients who co-ingested BZDs [11] and also in rats administered a combination of diazepam and tramadol [12]. In contrast, other researchers proposed an increase in morbidity and 
Fig. 3 The adverse effects of tramadol on different systems

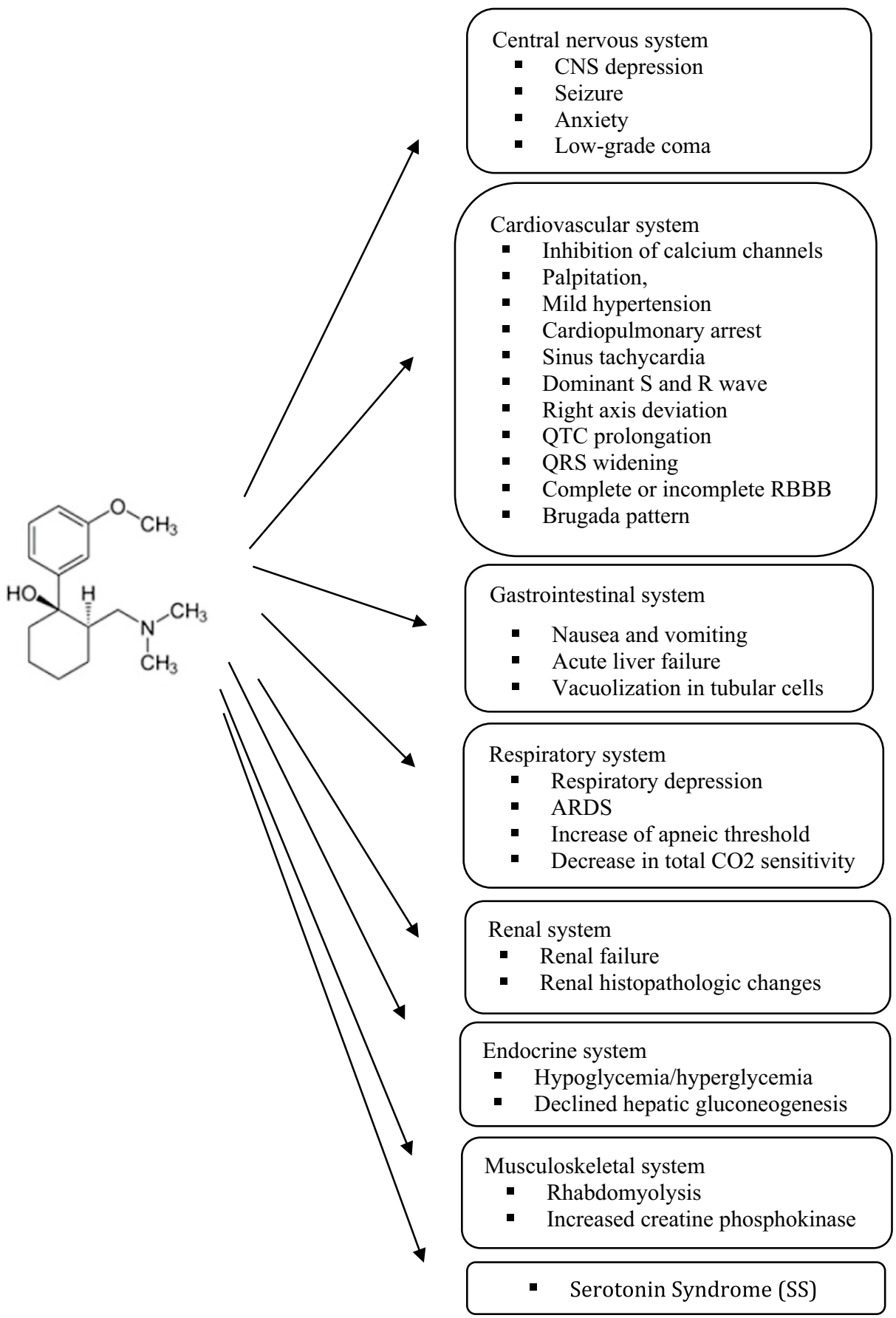

possibly lethality of tramadol overdoses when BZDs were used. [15]. On the other hand, while the evidence could not support the preventive effect of naloxone in such patients [54], seizures may be precipitated by injecting naloxone, accompanying high doses of tramadol [2, 7, 31, 60, 75]. Interestingly, recent meta-analyses have shown that the occurrences of seizures was not related to naloxone administration [67]. Along with serotonin, other possible systems have been proposed as being involved in precipitating tramadol-induced seizures, including histaminergic, dopaminergic, opioid and GABAergic neurotransmission [12]. Inhibition of GABAergic neurons and activation of glutamatergic neurons lead to seizures. Tramadol and metabolite M1 inhibit GABAA receptors at high concentrations and NMDA receptors at clinical concentrations [76]. Neurotoxicity after tramadol exposure is associated with serotonin and norepinephrine reuptake inhibition. However, the potent inhibition of GABA-A receptors at high doses of tramadol may explain the decreased seizure threshold [67] (Fig. 2). 


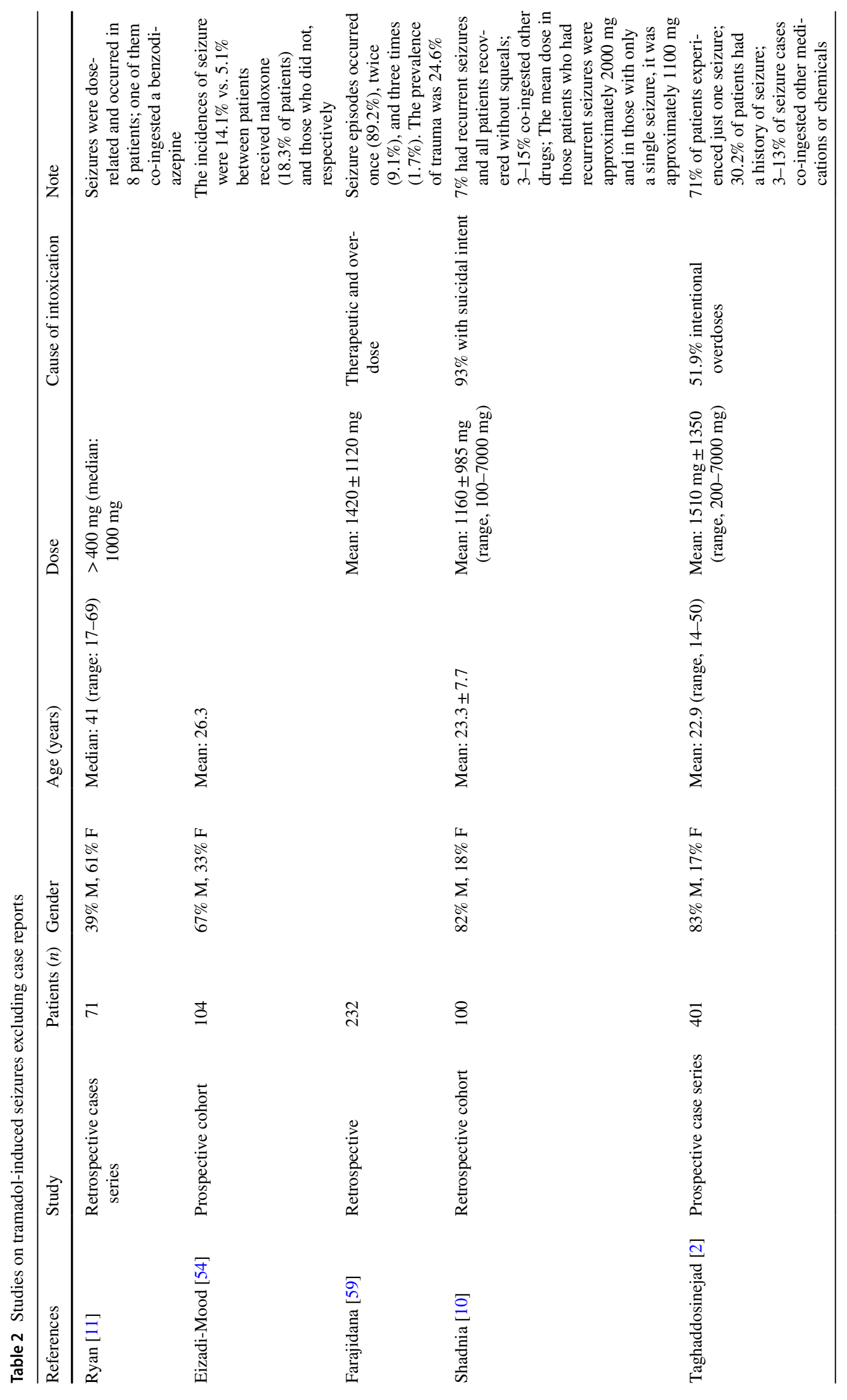




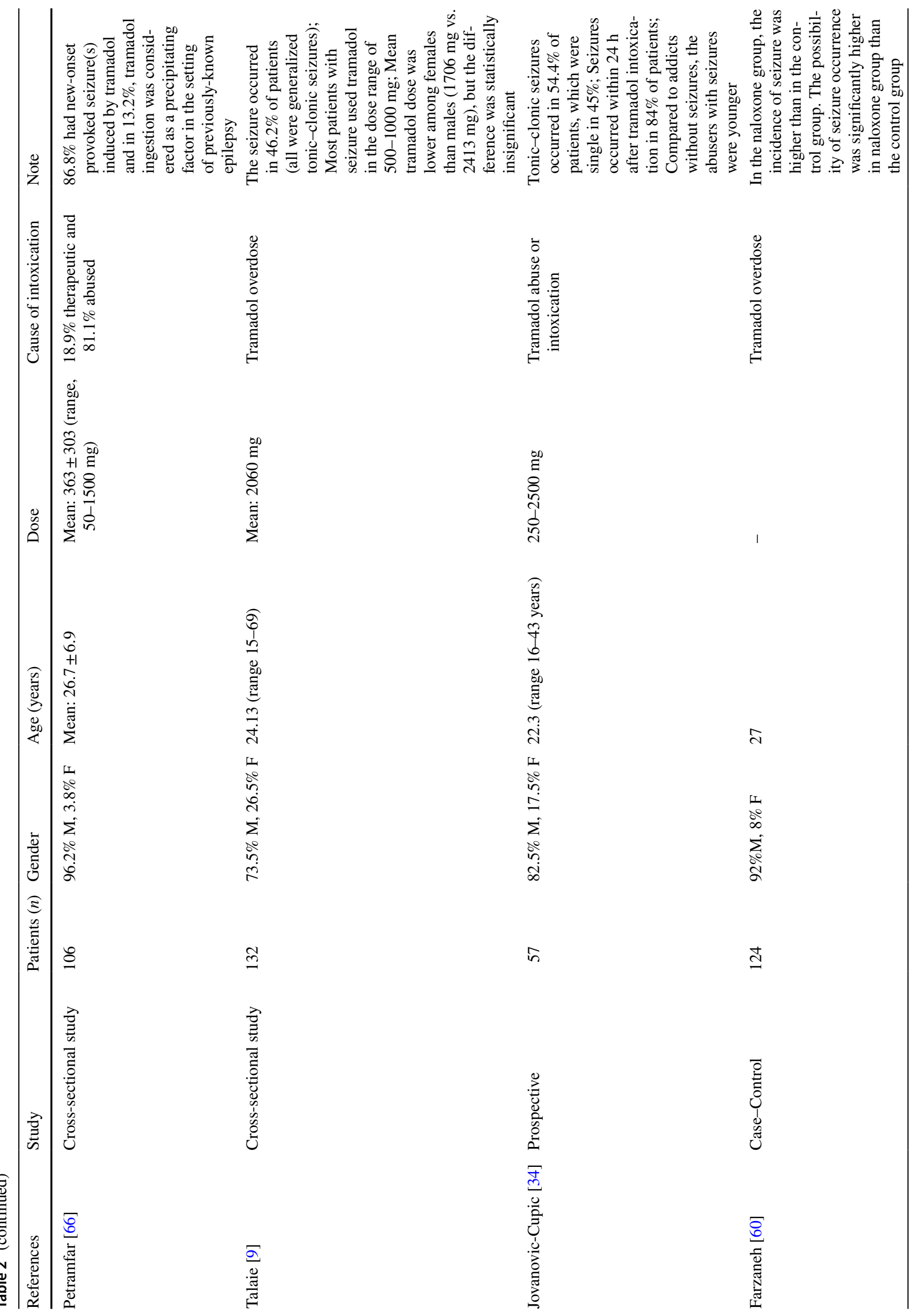




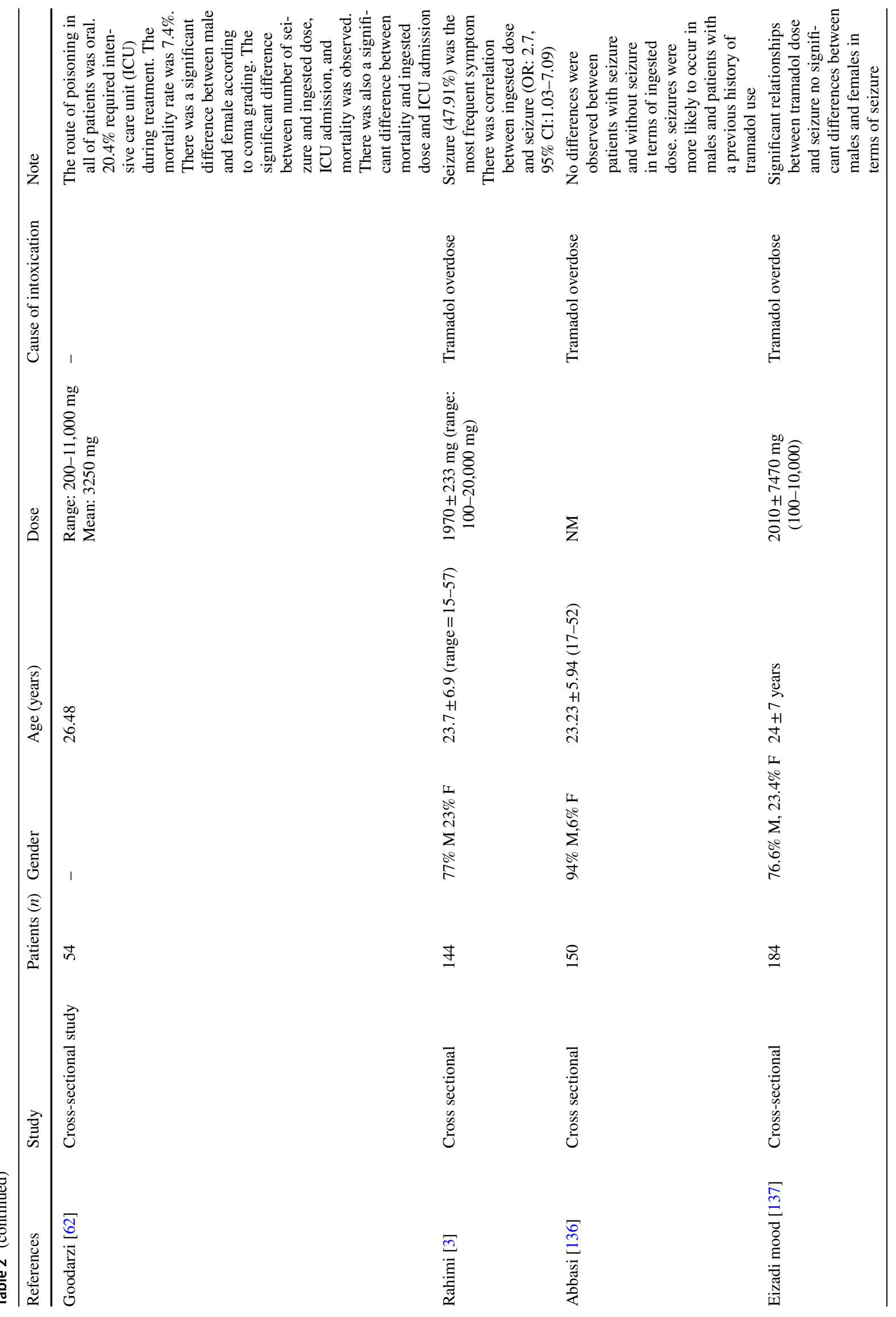




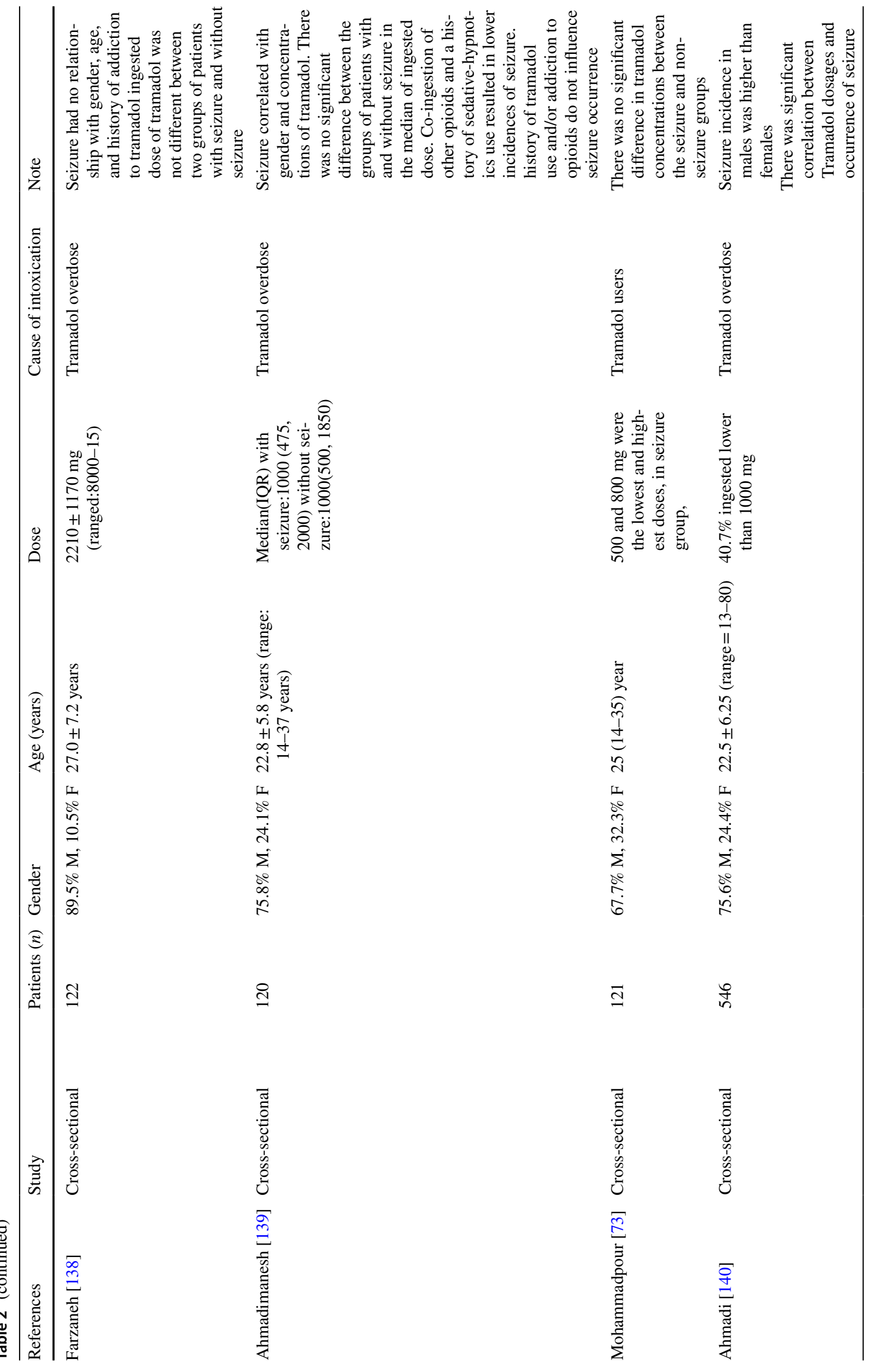




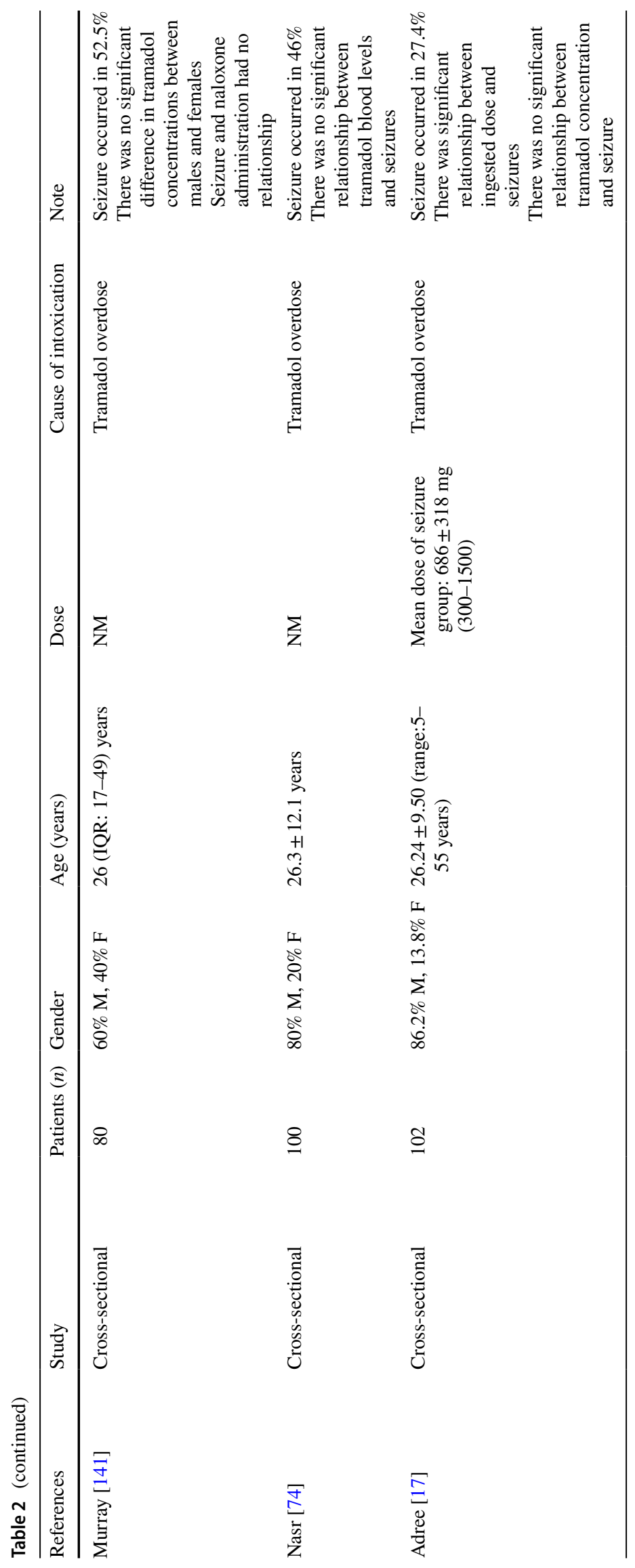




\section{Cardiovascular system}

Cardiac manifestations are expected in tramadol intoxication. Experimental studies demonstrated a negative inotropic effect [77] and histological changes including alterations in cell morphology, inflammatory cell infiltrates, and cell death [78] with high doses of tramadol. The mechanisms underlying the cardiac effect of tramadol at high doses have not been completely understood. Inhibition of L-type calcium channels by tramadol enantiomers $(\sim 60 \%)$ has been shown, but the racemic mixture produced significantly less effect $(\sim 30 \%)$. A direct effect on calcium channels or activation of a receptor-modulating calcium current has been proposed rather than activation of opioid receptors [79].

Cardio-toxicity symptoms range from palpitation and mild hypertension to life-threatening complications such as cardiopulmonary arrest. However, such severe manifestations are uncommon and were observed only at high doses of tramadol (> 5 g) or in CYP2D6 UMs [7, 11, 14, 50, 80-84]. As a treatment option, extracorporeal life support (ECLS) has been successfully used in refractory cardiogenic shocks [81, 83, 84]. In another report, a tramadol poisoned patient with clinical signs of acute pulmonary hypertension and right heart failure was observed [82].

In a report of tramadol-intoxicated patients without a previous history of heart disease, the most common types of ECG changes were sinus tachycardia (33\%), a dominant S wave in leads I and aVL (28\%), right axis deviation (24\%), QTC prolongation (18\%), QRS widening (6\%), and right bundle branch block (RBBB) (5\%). Increased PR interval occurred in none of the patients [49]. Brugada pattern and sinus bradycardia occur rarely $[49,85,86]$. Another study demonstrated right axis deviation (32\%), sinus tachycardia (31\%), QTC prolongation (25\%), prominent $\mathrm{R}$ waves in lead aVR (22\%), QRS widening (8\%), and complete or incomplete RBBB (5\%) in intoxicated patients [86]. Additionally, the authors concluded that the risk of seizures could not be predicted according to the changes found on ECG at presentation. None of the studies found a relationship between the ECG changes and the amount of drug ingested, or a history of tramadol use. In contrast, some studies proposed that tramadol induced seizure could lead to cardiac complications and reported higher levels of troponin I and creatine phosphokinase in patients experiencing seizures, compared to non-seizure subjects [73].

\section{Respiratory system}

Respiratory depression was not seen with therapeutic uses of tramadol [14]. It is more likely to happen when tramadol is taken with alcohol or other CNS depressants $[4,11]$. Although respiratory depression and apnea in oral pure tramadol poisoning is reported [87]. Anoxic brain damage may eventually happen secondarily to respiratory depression or arrest [36].

A large dose of tramadol, similar to other opioids, may cause central apnea. Studies within the same ethnic group demonstrated an apnea rate of $3.6 \%$ in adults vs. $15 \%$ in pediatric tramadol-intoxicated patients $[16,88]$. Renal impairment or patient's genetic background, such as being an UMs, could also be predisposing factors [89].

There is no evidence that tramadol directly targets the lungs. However, a solitary case of acute respiratory distress syndrome (ARDS) and pulmonary edema has been reported [90, 91]. Studies with animals and humans have shown an increase of apneic threshold and a decrease in total $\mathrm{CO}_{2}$ sensitivity due to tramadol $[92,93]$. Naloxone reversed these effects dramatically, while over half of the expected respiratory depression was maintained in animals after naloxone pretreatment [92].

Respiratory depression could happen at doses just above the therapeutic dose in children $(2 \mathrm{mg} / \mathrm{kg})$, and it has been more common among children presenting with respiratory acidosis. Moreover, it has been reported that the occurrence of apnea was statistically independent of the ingested dose in children [88] and dose-dependent in adults [16]. Therefore, the observation time of $12 \mathrm{~h}$ was recommended for all asymptomatic children who have ingested greater than the therapeutic dose of tramadol [88].

\section{Renal system}

There are only a few case reports of renal failure with higher doses of tramadol intoxication $[54,57,90]$. An experimental study found only minimal renal histopathologic changes limited to tubular cells with chronic therapeutic doses of tramadol. In addition, blood urea nitrogen (BUN and creatinine levels remained unchanged [52]. It has been proposed that tramadol induced seizure can lead to renal complications and kidney biochemical parameters which were reported to be significantly higher in patients experiencing seizures compared to the non-seizure patients [73].

\section{Musculoskeletal system}

Rhabdomyolysis and increased creatine phosphokinase (CPK) are rare but serious complications in tramadol intoxication [3, 57, 94, 95]. These observations have been proposed as a consequence of seizure but could not be confirmed in other studies [3]. It is important to diagnose and treat rhabdomyolysis quickly to prevent acute renal failure and life-threatening complications. Tongue laceration in a tramadol-poisoned unconscious patient is also considered a clinical indicator of generalized tonic-clonic seizures [96]. 


\section{Endocrine system}

Another possible major side effect of tramadol overdose is hypoglycemia in adults [97-99] and children [100] that seems to be dose-independent [97, 98]. In diabetic rats, the activation of $\mu$-opioid receptors by tramadol enhanced the use of glucose and decreased hepatic gluconeogenesis that caused it [101]. Some studies also reported hyperglycemia due to tramadol poisoning $[98,102,103]$. It has been suggested that monoaminergic pathways, which are effective on the analgesic action of tramadol, may have a role in the hyperglycemic effects of the drug [103]. Serial blood glucose level monitoring has been suggested for early detection and management of hypo and hyperglycemia in tramadol overdose and intoxication [98]. A recent systematic review revealed that hypoglycemia is more likely to occur after tramadol use with both therapeutic use and in overdose. Importantly, all studies on tramadol use in diabetes reported hypoglycemia [104].

\section{Serotonin syndrome (SS)}

Tramadol PMs are at risk for elevated $(+)$ tramadol levels, which has serotonergic reuptake inhibition activity [1]. An animal study found a potential for serotonin-like syndrome with tramadol alone in rodents lacking one or two copies of serotonin transporter. This finding may indicate genetic susceptibility to serotonin syndrome. In humans, however, serotonin syndrome is unlikely in isolated tramadol intoxication and has been reported in co-ingestion with other medications, especially serotonergic antidepressants and atypical antipsychotics [1, 11]. Pre-treatment with benzodiazepine such as chlordiazepoxide and diazepam could prevent tramadol overdose-induced serotonin syndrome as demonstrated in some animal and human studies [12, 94, 105]. In addition, the occurrence of serotonin syndrome in an infant intoxicated with tramadol has been reported [106]. Fujimoto et al. (2015) suggested that tramadol-induced seizures were not associated with inhibition of serotonin uptake and that these seizures were distinct from serotonin syndrome [107]. A potential mechanism for tramadol induced serotonin syndrome has been illustrated in Fig. 2.

\section{Mortality}

Tramadol-induced mortality is increasing in different countries [4, 91, 108-113]. Fatal tramadol intoxications are uncommon except in cases of co-ingestion with other drugs, particularly, the CNS depressants, most commonly benzodiazepines and ethanol [4, 7, 36, 80, 84, 114-123]. The majority of deaths have been reported before patients' arrival at hospitals. Consequently, the clinical course before death is not well known, and most cases occur without any witnesses $[36,91,116]$. The most common cause of death is cardiopulmonary arrest $[7,9,124,125]$. One potential mechanism of tramadol intoxication death could be attributed to respiratory depression induced by increased expression of GABA(A) alpha1 and GABA(B)1 in the medulla oblongata solitary nucleus and ambiguous nucleus [126]. Addiction, depression, and previous history of seizure seem to be risk factors for tramadol associated mortality [4]. Curiously, fatal concentration of tramadol in the cases of co-ingestion were significantly lower $(0.15$ to $39 \mathrm{mg} / \mathrm{L})$ in comparison with single tramadol poisoning. This low concentration of tramadol may overlap with the concentrations in therapeutic doses (0.1-0.3 mg/L) [4].

M1/M2 concentration ratio has been recommended to serve as an indicator of the time-lapse between the ingestion of tramadol and death with an M1/M2 concentration ratio of more than one, representing acute death. In contrast, a ratio of less than one displays a more extended time lapse $[117,127]$.

\section{Tramadol blood concentration and its complications}

Tramadol has an oral bioavailability of $68 \%$ after a single dose and $90-100 \%$ after multiple doses, reaching peak serum concentrations within $2 \mathrm{~h}$ [124]. It is well absorbed after oral administration (approximately 75\%) [127]. The half-life of tramadol in overdose was reported as $9.24 \mathrm{~h}$, which was positively correlated with higher concentrations [42]. The usual concentrations following $50-100 \mathrm{mg}$ doses, range up to $0.3 \mathrm{mg} / \mathrm{L}$ [124], and toxic effects may occur at blood concentrations above $1 \mathrm{mg} / \mathrm{L}$ [127]. In pure tramadol poisoning induced fatal outcomes, blood tramadol concentrations of $1.6-61.8 \mathrm{mg} / \mathrm{L}$ have been reported $[36,115,119$, 127]. The minimum lethal dose reported in the literature is $1.6 \mathrm{mg} / \mathrm{L}$. It reveals a lethal blood tramadol concentration several times higher than the normal therapeutic range of $0.1-0.3 \mathrm{mg} / \mathrm{L}$. The literature regarding the relationship between tramadol serum concentrations and manifestations of tramadol overdose is limited. Some studies among patients with tramadol intoxication reported an elevated serum concentrations of tramadol and cardiac complications $[81,85]$.

\section{Treatment}

Treatment should be based on conservative approaches, including breathing, maintenance of airway, circulation, fluid resuscitation, oxygen therapy, and diazepam administration for managing seizure and agitation [57, 128, 129]. Patients should be examined for an increase in CPK and potential acute renal failure that may occur up to the following 2 days $[57,128]$. 
Gastrointestinal decontamination should be carried out for referring patients within the first two hours after ingestion without any contraindications $[7,14,50]$.

In severe toxicities that occur after ingestion of large amounts of sustained-release tramadol, multiple-dose activated charcoal may be a treatment of choice, if no contraindication is present $[128,130]$. Because of the early onset of seizures following tramadol ingestion, it has been suggested to administer charcoal after securing the airway to avoid aspiration pneumonitis [14].

Intubation/ventilation and administration of naloxone are implemented to treat respiratory depression or tramadolinduced apnea [16, 70, 131, 132]. Some studies suggested that naloxone administration might cause seizure in tramadol intoxication and recommended against routine administration of naloxone for treating tramadol poisoning $[10,60$, 133]. However, a recent meta-analysis showed that naloxone administration does not increase the risk of seizure in tramadol poisoned patients [67]. Seizures due to tramadol do not respond to naloxone but are relieved with benzodiazepines. Naloxone can be used for the treatment of post-seizure complaints [134]. A combination of diazepam/naloxone is reported as an efficient antidote to reverse tramadol-induced CNS toxicity [75]. Due to the low risk of multiple seizures in tramadol toxicity, anticonvulsant treatment should not be routinely prescribed even for cases of initial seizures [10].

Treatment of SS is also conservative and involves the withdrawal of the culpable drug and external cooling. Up to $42 \%$ of the patients are likely to require ICU, and most of them recover 12-24 h later [116]. Efficacy of intravenous lipid emulsion in tramadol poisoning in rabbits has been reported in some studies [135].

\section{Conclusions}

Tramadol poisoning can affect multiple organ systems, including the gastrointestinal, central nervous, cardiovascular, respiratory, renal, and endocrine systems, as well as, cause rhabdomyolysis and serotonin syndrome. Physicians must be aware of its adverse effects, substantial abuse potential, and drug interactions to weigh its risk-benefits for pain management. Alternative therapies might be considered in patients with a previous history of overdose to prevent further intoxications.

It is important to note that pharmacodynamics of tramadol including different enantiomers, genetic polymorphism, differences in affinity to the receptors, and metabolism play an important role in understanding why studies have failed to show a strong relationship between tramadol blood concentrations and occurrence of specific adverse effects. It also highlights the importance of dosage adjustment of tramadol according to an individual's metabolic capacity, which is not currently practiced in most clinics.

Author contribution $\mathrm{SN}, \mathrm{CH}, \mathrm{RD}, \mathrm{RL}, \mathrm{MA}, \mathrm{OM}$ contributed to the conception, design, and preparation of the manuscript. SN, OM conducted the data collection and contributed to acquisition and interpretation. SN, CH, RD, RL, MA, OM made substantial contributions in drafting the manuscript and revising it critically for important intellectual content. All authors have read and approved the final version of the manuscript.

\section{Compliance with ethical standards}

Conflict of interest The authors have no relevant affiliations or financial involvement with any organization or entity with a financial interest in or financial conflict with the subject matter or materials discussed in the manuscript. This includes employment, consultancies, honoraria, stock ownership or options, expert testimony, grants or patents received or pending, or royalties.

Ethical approval No ethical approval was required for the preparation of this type of article.

Open Access This article is licensed under a Creative Commons Attribution 4.0 International License, which permits use, sharing, adaptation, distribution and reproduction in any medium or format, as long as you give appropriate credit to the original author(s) and the source, provide a link to the Creative Commons licence, and indicate if changes were made. The images or other third party material in this article are included in the article's Creative Commons licence, unless indicated otherwise in a credit line to the material. If material is not included in the article's Creative Commons licence and your intended use is not permitted by statutory regulation or exceeds the permitted use, you will need to obtain permission directly from the copyright holder. To view a copy of this licence, visit http://creativecommons.org/licenses/by/4.0/

\section{References}

1. Kaye AD (2015) Tramadol, pharmacology, side effects, and serotonin syndrome: a review. Pain Physician 18:395-400

2. Taghaddosinejad F, Mehrpour O, Afshari R, Seghatoleslami A, Abdollahi M, Dart RC (2011) Factors related to seizure in tramadol poisoning and its blood concentration. J Med Toxicol 7:183

3. Rahimi HR, Soltaninejad K, Shadnia S (2014) Acute tramadol poisoning and its clinical and laboratory findings. J Res Med Sci 19:855

4. Randall C, Crane J (2014) Tramadol deaths in Northern Ireland: a review of cases from 1996 to 2012. J Forensic Leg Med 23:32-36

5. Miotto K, Cho AK, Khalil MA, Blanco K, Sasaki JD, Rawson R (2017) Trends in tramadol: pharmacology, metabolism, and misuse. Anesth Analg 124:44-51

6. United Nations. International Narcotics Control Board 2013. Report of the International Narcotics Control Board for 2013. New York: United Nations. http://www.incb.org/documents/ Publications/AnnualReports/AR2013/English/Global_devel opments_in_the_non-medical_use_of_tramadol.pdf. Accessed 30 May 2019

7. Shadnia S, Soltaninejad K, Heydari K, Sasanian G, Abdollahi M (2008) Tramadol intoxication: a review of 114 cases. Hum Exp Toxicol 27:201-205 
8. Häkkinen M, Vuori E, Ojanperä I (2014) Prescription opioid abuse based on representative postmortem toxicology. Forensic Sci Int 245:121-125

9. Talaie H, Panahandeh R, Fayaznouri MR, Asadi Z, Abdollahi $M$ (2009) Dose-independent occurrence of seizure with tramadol. J Med Toxicol 5:63-67

10. Shadnia S, Brent J, Mousavi-Fatemi K, Hafezi P, Soltaninejad K (2012) Recurrent seizures in tramadol intoxication: implications for therapy based on 100 patients. Basic Clin Pharmacol Toxicol 111:133-136

11. Ryan NM, Isbister GK (2015) Tramadol overdose causes seizures and respiratory depression but serotonin toxicity appears unlikely. Clin Toxicol 53:545-550

12. Lagard C, Chevillard L, Malissin I, Risède P, Callebert J, Labat L et al (2016) Mechanisms of tramadol-related neurotoxicity in the rat: Does diazepam/tramadol combination play a worsening role in overdose? Toxicol Appl Pharmacol 310:108-119

13. Abdel-Hamid IA, Andersson K-E, Waldinger MD, Anis TH (2016) Tramadol abuse and sexual function. Sex Med Rev 4:235-246

14. Marquardt KA, Alsop JA, Albertson TE (2005) Tramadol exposures reported to statewide poison control system. Ann Pharmacother 39:1039-1044

15. Clarot F, Goulle J, Vaz E, Proust B (2003) Fatal overdoses of tramadol: is benzodiazepine a risk factor of lethality? Forensic Sci Int 134:57-61

16. Hassanian-Moghaddam H, Farajidana H, Sarjami S, Owliaey H (2013) Tramadol-induced apnea. Am J Emerg Med 31:26-31

17. Adree H, Fouad H, Waleed E, Sherief M (2018) Incidence and factors influencing acute tramadol toxicity-inducing seizures in Damietta Governorate. Mansoura J Forensic Med Clin Toxicol 26:155-167

18. Halawa $\mathrm{H}$ (2013) Clinical study of acute tramadol poisoning in the poison control center, Ain Shams University in 2012. Ain Shams J Forensic Med Clin Toxicol 21:20-26

19. Talaie H, Nasiri S, Gheisari M, Dadkhahfar S, Ahmadi S (2018) bservational study of dermatological manifestations in patients admitted to a tertiary poison center in Iran. Turk J Med Sci 48:136-141

20. Bassiony MM, Youssif UM, Hussein RA, Saeed M (2016) Psychiatric comorbidity among Egyptian patients with opioid use disorders attributed to tramadol. J Addict Med 10:262-268

21. Wu W, McKown L, Liao S (2002) Metabolism of the analgesic drug ULTRAM ${ }^{\circledR}$ (tramadol hydrochloride) in humans: APIMS and MS/MS characterization of metabolites. Xenobiotica 32:411-425

22. Barbosa J, Faria J, Queirós O, Moreira R, Carvalho F, DinisOliveira RJ (2016) Comparative metabolism of tramadol and tapentadol: a toxicological perspective. Drug Metab Rev 48:577-592

23. Grond S, Sablotzki A (2004) Clinical pharmacology of tramadol. Clin Pharmacokinet 43:879-923

24. Gong L, Stamer UM, Tzvetkov MV, Altman RB, Klein TE (2014) PharmGKB summary: tramadol pathway. Pharmacogenet Genom 24:374

25. Doostmohammadi M, Rahimi H-R (2020) ADME and toxicity considerations for tramadol: from basic research to clinical implications. Expert Opin Drug Metab Toxicol 16(7):627-640

26. Gan SH, Ismail R, Adnan WAW, Zulmi W (2007) Impact of CYP2D6 genetic polymorphism on tramadol pharmacokinetics and pharmacodynamics. Mol Diagn Ther 11:171-181

27. Stamer U, Stüber F (2007) Codeine and tramadol analgesic efficacy and respiratory effects are influenced by CYP2D6 genotype. Anaesthesia 62:1294-1295
28. Halling J, Weihe P, Brosen K (2008) CYP2D6 polymorphism in relation to tramadol metabolism: a study of faroese patients. Ther Drug Monit 30:271-275

29. Haufroid V, Hantson P (2015) CYP2D6 genetic polymorphisms and their relevance for poisoning due to amfetamines, opioid analgesics and antidepressants. Clin Toxicol 53:501-510

30. Raffa RB (2008) Basic pharmacology relevant to drug abuse assessment: tramadol as example. J Clin Pharm Ther 33:101-108

31. Raffa RB, Stone DJ (2008) Unexceptional seizure potential of tramadol or its enantiomers or metabolites in mice. J Pharmacol Exp Ther 325:500-506

32. Schulz M, Iwersen-Bergmann S, Andresen H, Schmoldt A (2012) Therapeutic and toxic blood concentrations of nearly 1,000 drugs and other xenobiotics. Crit Care 16:R136

33. Ingelman-Sundberg M, Oscarson M, McLellan RA (1999) Polymorphic human cytochrome P450 enzymes: an opportunity for individualized drug treatment. Trends Pharmacol Sci 20:342-349

34. Jovanović-Čupić V, Martinović Ž, Nešić N (2006) Seizures associated with intoxication and abuse of tramadol. Clin Toxicol 44:143-146

35. Pedersen RS, Damkier P, Brosen K (2005) Tramadol as a new probe for cytochrome P450 2D6 phenotyping: a population study. Clin Pharmacol Ther 77:458-467

36. De Decker K, Cordonnier J, Jacobs W, Coucke V, Schepens P, Jorens PG (2008) Fatal intoxication due to tramadol alone: case report and review of the literature. Forensic Sci Int 175:79-82

37. Gillen C, Haurand M, Kobelt DJ, Wnendt S (2000) Affinity, potency and efficacy of tramadol and its metabolites at the cloned human $\mu$-opioid receptor. Naunyn Schmiedebergs Arch Pharmacol 362:116-121

38. Enggaard TP, Poulsen L, Arendt-Nielsen L, Brøsen K, Ossig J, Sindrup SH (2006) The analgesic effect of tramadol after intravenous injection in healthy volunteers in relation to CYP2D6. Anesth Analg 102:146-150

39. Raffa RB, Friderichs E, Reimann W, Shank RP, Codd EE, Vaught JL et al (1993) Complementary and synergistic antinociceptive interaction between the enantiomers of tramadol. J Pharmacol Exp Ther 267:331-340

40. Raffa RB, Buschmann H, Christoph T, Eichenbaum G, Englberger W, Flores CM et al (2012) Mechanistic and functional differentiation of tapentadol and tramadol. Expert Opin Pharmacother 13:1437-1449

41. Goeringer KE, Logan BK, Christian GD (1997) Identification of tramadol and its metabolites in blood from drug-related deaths and drug-impaired drivers. J Anal Toxicol 21:529-537

42. Khosrojerdi H, Talesh GA, Danaei GH, Saremi SS, Adab A, Afshari R (2015) Tramadol half life is dose dependent in overdose. Daru 23:22

43. Gibson TP (1996) Pharmacokinetics, efficacy, and safety of analgesia with a focus on tramadol HCl. Am J Med 101:S47-S53

44. Costa I, Oliveira A, de Pinho PG, Teixeira HM, Moreira R, Carvalho $\mathrm{F}$ et al (2013) Postmortem redistribution of tramadol and O-desmethyltramadol. J Anal Toxicol 37:670-675

45. Mehrpour O, Sharifi M, Zamani N (2015) Tramadol poisoning. In: Andreazza AC, Scola G (ed) Toxicology studies-cells, drugs and environment: BoD, Books on Demand

46. Tsutaoka BT, Ho RY, Fung SM, Kearney TE (2015) Comparative toxicity of tapentadol and tramadol utilizing data reported to the national poison data system. Ann Pharmacother 49:1311-1316

47. Dhagudu NK, Erravalli A, Sarkar S, Chadda RK (2019) Tramadol-related adverse drug reactions at an addiction psychiatry setting: a cross-sectional analysis. Indian J Psychol Med 41:593

48. Pedersen RS, Damkier P, Christensen MMH, Brosen K (2013) A cytochrome $\mathrm{P} 450$ phenotyping cocktail causing unexpected adverse reactions in female volunteers. Eur J Clin Pharmacol 69:1997-1999 
49. Ghamsari AA, Dadpour B, Najari F (2016) Frequency of electrocardiographic abnormalities in tramadol poisoned patients; a brief report. Emerg 4:151

50. Spiller HA, Gorman SE, Villalobos D, Benson BE, Ruskosky DR, Stancavage MM et al (1997) Prospective multicenter evaluation of tramadol exposure. Clin Toxicol 35:361-364

51. Khosrojerdi H, Afshari R, Mehrpour O (2013) Should activated charcoal be given after tramadol overdose? Daru 21:46

52. Atici S, Cinel I, Cinel L, Doruk N, Eskandari G, Oral U (2005) Liver and kidney toxicity in chronic use of opioids: an experimental long term treatment model. J Biosci 30:245-252

53. El-Hussuna A, Arnesen RB, Rosenberg J (2010) Tramadol poisoning with hyperamylasemia. BMJ Case Rep 2010:bcr0320102821

54. Eizadi-Mood N, Ozcan D, Sabzghabaee AM, Mirmoghtadaee P, Hedaiaty M (2014) Does naloxone prevent seizure in tramadol intoxicated patients? Int J Prev Med 5:302

55. Mehrpour O (2013) Addiction and seizure ability of tramadol in high-risk patients. Indian J Anaesth 57:86-87

56. Taheri MS, Noori M, Shakiba M, Jalali AH (2011) Brain CTscan findings in unconscious patients after poisoning. Int $\mathrm{J}$ Biomed Sci 7:1

57. Afshari R, Ghooshkhanehee H (2009) Tramadol overdose induced seizure, dramatic rise of CPK and acute renal failure. J Pak Med Assoc 59:178

58. Bekjarovski N, Chaparoska D, Radulovikj-Bekjarovska S (2012) Seizures after use and abuse of tramadol. Contributions of Macedonian Academy of Sciences \& Arts, p. 33

59. Farajidana H, Hassanian-Moghaddam H, Zamani N, SanaeiZadeh H (2012) Tramadol-induced seizures and trauma. Eur Rev Med Pharmacol Sci 16:34-37

60. Farzaneh E, Mostafazadeh B, Mehrpour O (2012) Seizurogenic effects of low-dose naloxone in tramadol overdose. Iran J Pharmacol Ther 11:6

61. Gardner JS, Blough D, Drinkard CR, Shatin D, Anderson G, Graham D et al (2000) Tramadol and seizures: a surveillance study in a managed care population. Pharmacother 20:1423-1431

62. Goodarzi F, Mehrpour O, Eizadi-Mood N (2011) A study to evaluate factors associated with seizure in tramadol poisoning in Iran. Indian J Med Forensic Med Toxicol 5:66-69

63. Mazor SS, Feldman KW, Sugar NF, Sotero M (2008) Pediatric tramadol ingestion resulting in seizurelike activity: a case series. Pediatr Emerg Care 24:380-381

64. Mehrpour M (2005) Intravenous tramadol-induced seizure: two case reports. Iran J Pharmacol Ther 4:146

65. Mehrpour O, Taghaddosi-Nejad F, Seghatoleslami A, Chalaki N, Afshari R (2010) Tramadol poisoning induced seizure. Toxicol Lett 196:S79-S80

66. Petramfar P, Haghighi AB (2010) Tramadol induced seizure: report of 106 patients. Iran Red Crescent Med J 12:49

67. Nakhaee S, Amirabadizadeh A, Brent J, Miri-Moghaddam E, Foadoddini M, Farrokhfall K et al (2019) Tramadol and the occurrence of seizures: a systematic review and meta-analysis. Crit Rev Toxicol 49:710-723

68. Rezk NN, Khater AS, Sarhan NM (2012) Tramadol induced seizures; in relation to patient criteria and tramadol dose. Egypt $\mathrm{J}$ Forensic Sci Appl Toxicol 220:1-9

69. Thundiyil JG, Kearney TE, Olson KR (2007) Evolving epidemiology of drug-induced seizures reported to a Poison Control Center System. J Med Toxicol 3:15-19

70. Grosek S, Mozina M, Grabnar I, Primozic J (2009) Diagnostic and therapeutic value of naloxone after intoxication with tramadol in a young girl. Pediatr Int 51:842-843

71. Correia MS, Whitehead E, Cantrell FL, Lasoff DR, Minns AB (2019) A 10-year review of single medication double-dose ingestions in the nation's largest poison control system. Clin Toxicol 57:31-35

72. Abuelfadl AA, El-Ebiary AA, Soliman MA (2016) Tramadol blood level and prediction of seizures in patients with acute tramadol poisoning. Mansoura J Forensic Med Clin Toxicol 24:35-47

73. Mohammadpour A, Ashkezari MD, Farahmand B, Shokrzadeh M (2019) Demographic characteristics and functional performance of the kidneys and hearts of patients with acute tramadol toxicity. Drug Res 69:207-210

74. Nasr MA, Mahmoud SF, Mohammed MA, El-samie HSA (2018) A study of clinical and laboratory picture of acute tramadol toxicity in Damietta governorate. Mansoura J Forensic Med Clin Toxicol 26:143-153

75. Lagard C, Malissin I, Indja W, Risède P, Chevillard L, Mégarbane B (2018) Is naloxone the best antidote to reverse tramadolinduced neuro-respiratory toxicity in overdose? An experimental investigation in the rat. Clin Toxicol 56:737-743

76. Hara K, Minami K, Sata T (2005) The effects of tramadol and its metabolite on glycine, $\gamma$-aminobutyric AcidA, and N-methyl-daspartate receptors expressed in Xenopus oocytes. Anesth Analg 100:1400-1405

77. Raimundo JM, Sudo RT, Pontes LB, Antunes F, Trachez MM, Zapata-Sudo $G$ (2006) In vitro and in vivo vasodilator activity of racemic tramadol and its enantiomers in Wistar rats. Eur $\mathrm{J}$ Pharmacol 530:117-123

78. Faria J, Barbosa J, Leal S, Afonso LP, Lobo J, Moreira R et al (2017) Effective analgesic doses of tramadol or tapentadol induce brain, lung and heart toxicity in Wistar rats. Toxicol 385:38-47

79. Medei E, Raimundo JM, Nascimento JHM, Trachez MM, Sudo RT, Zapata-Sudo G (2011) Inhibition of L-type calcium current by tramadol and enantiomers in cardiac myocytes from rats. Arq Bras Cardiol 97:324-331

80. Perdreau E, Iriart X, Mouton J-B, Jalal Z, Thambo J-B (2015) Cardiogenic shock due to acute tramadol intoxication. Cardiovasc Toxicol 15:100-103

81. Belin N, Clairet A-L, Chocron S, Capellier G, Piton G (2017) Refractory cardiogenic shock during tramadol poisoning: a case report. Cardiovasc Toxicol 17:219-222

82. Garrett P (2004) Tramadol overdose and serotonin syndrome manifesting as acute right heart dysfunction. Anaesth Intensive Care 32:575-577

83. Elkalioubie A, Allorge D, Robriquet L, Wiart J-F, Garat A, Broly $F$ et al (2011) Near-fatal tramadol cardiotoxicity in a CYP2D6 ultrarapid metabolizer. Eur J Clin Pharmacol 67:855-858

84. Daubin C, Quentin C, Goullé J-P, Guillotin D, Lehoux P, Lepage O et al (2007) Refractory shock and asystole related to tramadol overdose. Clin Toxicol 45:961-964

85. Cole JB, Sattiraju S, Bilden EF, Asinger RW, Bertog SC (2012) Isolated tramadol overdose associated with Brugada ECG pattern. Pacing Clin Electrophysiol 35:e219-e221

86. Emamhadi M, Sanaei-Zadeh H, Nikniya M, Zamani N, Dart RC (2012) Electrocardiographic manifestations of tramadol toxicity with special reference to their ability for prediction of seizures. Am J Emerg Med 30:1481-1485

87. Hassanian-Moghaddam H (2013) Oral pure tramadol exposure like other opioids can cause apnea-why not be careful? Am J Emerg Med 31:410-411

88. Hassanian-Moghaddam H, Farnaghi F, Rahimi M (2015) Tramadol overdose and apnea in hospitalized children, a review of 20 cases. Res Pharm Sci 10:544

89. Stamer UM, Stüber F, Muders T, Musshoff F (2008) Respiratory depression with tramadol in a patient with renal impairment and CYP2D6 gene duplication. Anesth Analg 107:926-929

90. Wang S-Q, Li C-S, Song Y-G (2009) Multiply organ dysfunction syndrome due to tramadol intoxication alone. Am J Emerg Med 27:903.e5-903.e7 
91. Gioia S, Lancia M, Bacci M, Suadoni F (2017) Two fatal intoxications due to tramadol alone: autopsy case reports and review of the literature. Am J Forensic Med Pathol 38:345-348

92. Teppema LJ, Nieuwenhuijs D, Olievier CN, Dahan A (2003) Respiratory depression by tramadol in the catinvolvement of opioid receptors. Anesthesiology 98:420-427

93. Nieuwenhuijs D, Bruce J, Drummond G, Warren P, Dahan A (2001) Influence of oral tramadol on the dynamic ventilatory response to carbon dioxide in healthy volunteers. $\mathrm{Br} \mathrm{J}$ Anaesth $87: 860-865$

94. Tashakori A, Afshari R (2010) Tramadol overdose as a cause of serotonin syndrome: a case series. Clin Toxicol 48:337-341

95. Khan FY, Yousef H, Errayes M (2010) Tramadol toxicityinduced rhabdomyolysis. J Emerg Trauma Shock 3:421

96. Sanaei-Zadeh H (2013) Tramadol intoxication and tongue laceration. N Z Med J 126:113-114

97. Mugunthan N, Davoren P (2012) Danger of hypoglycemia due to acute tramadol poisoning. Endocr Pract 18:e151-e152

98. Nasouhi S, Talaie H, Pajoumand A, Aghapour S, Rahimi M, Khorasani AG et al (2015) Hypo and hyperglycemia among tramadol overdose patients in Loghman Hakim Hospital, Tehran. Iran Pak J Pharm Sci 28:1959-1963

99. Abadie D, Durrieu G, Roussin A, Montastruc J-L (2013) "Serious" adverse drug reactions with tramadol: a 2010-2011 pharmacovigilance survey in France. Therapie 68:77-84

100. Aliyu I, Kyari F, Ibrahim Z (2016) Hypoglycemia in a child with tramadol poisoning. Saudi J Med Med Sci 4:35

101. Cheng J-T, Liu I-M, Chi T-C, Tzeng T-F, Lu F-H, Chang CJ (2001) Plasma glucose-lowering effect of tramadol in streptozotocin-induced diabetic rats. Diabetes 50:2815-2821

102. Fouad S, Hassan N, Nassief N, El-Halawany F, Hussien R (2015) Critical score as a predictor for progression of tramadol intoxication. J Clin Toxicol 5(2161-0495): 1000249

103. Kara H, Karci A, Gümüştekin M, Örmen M, Taşdöğen A, Elar $Z$ (2013) The effect of tramadol on blood glucose levels in rats. Open J Anesthesiol 3:18

104. Nakhaee S, Brent J, Hoyte C, Farrokhfall K, Shirazi M, Askari $M$ et al (2020) The effect of tramadol on blood glucose concentrations: a systematic review. Expert Rev Clin Pharmacol 13(5):531-543

105. Mansouripour SM, Afshari R (2013) Chlordiazepoxide preventive effect on tramadol overdose induced serotonin syndrome evaluated by Hunter and Radomski criteria: a clinical trial. Toxicol Int 20:126

106. Maréchal C, Honorat R, Claudet I (2011) Serotonin syndrome induced by tramadol intoxication in an 8-month-old infant. Pediatr Neurol 44:72-74

107. Fujimoto Y, Funao T, Suehiro K, Takahashi R, Mori T, Nishikawa K (2015) Brain serotonin content regulates the manifestation of tramadol-induced seizures in ratsdisparity between tramadol-induced seizure and serotonin syndrome. Anesthesiology 122:178-189

108. Iravani FS, Akhgari M, Jokar F, Bahmanabadi L (2010) Current trends in tramadol-related fatalities, Tehran, Iran 2005-2008. Subst Use Misuse 45:2162-2171

109. Häkkinen M, Launiainen T, Vuori E, Ojanperä I (2012) Comparison of fatal poisonings by prescription opioids. Forensic Sci Int 222:327-331

110. Hawton K, Ferrey A, Casey D, Wells C, Fuller A, Bankhead C et al (2019) Relative toxicity of analgesics commonly used for intentional self-poisoning: a study of case fatality based on fatal and non-fatal overdoses. J Affect Disord 246:814-819

111. Kim E, Park Y, Ha H, Chung H (2016) Patterns of drugs \& poisons in southern area of South Korea in 2014. Forensic Sci Int 269:50-55
112. Alinejad S, Zamani N, Abdollahi M, Mehrpour O (2017) A narrative review of acute adult poisoning in Iran. Iran J Med Sci 42:327

113. Handley S, Flanagan R (2014) Drugs and other chemicals involved in fatal poisoning in England and Wales during 2000 2011. Clin Toxicol 52:1-12

114. Tjäderborn M, Jönsson AK, Hägg S, Ahlner J (2007) Fatal unintentional intoxications with tramadol during 1995-2005. Forensic Sci Int 173:107-111

115. Clarkson JE, Lacy JM, Fligner CL, Thiersch N, Howard J, Harruff RC et al (2004) Tramadol (Ultram $®$ ) concentrations in death investigation and impaired driving cases and their significance. Iran J Med Sci 49:1101-1105

116. Loughrey M, Loughrey C, Johnston S, O'Rourke D (2003) Fatal hepatic failure following accidental tramadol overdose. Forensic Sci Int 134:232-233

117. Moore KA, Cina SJ, Jones R, Selby DM, Levine B, Smith ML (1999) Tissue distribution of tramadol and metabolites in an overdose fatality. Am J Forensic Med Pathol 20:98-100

118. Musshoff F, Madea B (2001) Fatality due to ingestion of tramadol alone. Forensic Sci Int 116:197-199

119. De Backer B, Renardy F, Denooz R, Charlier C (2010) Quantification in postmortem blood and identification in urine of tramadol and its two main metabolites in two cases of lethal tramadol intoxication. J Anal Toxicol 34:599-604

120. Lusthof KJ, Zweipfenning PG (1998) Suicide by tramadol overdose. J Anal Toxicol 22:260

121. Ripple MG, Pestaner JP, Levine BS, Smialek JE (2000) Lethal combination of tramadol and multiple drugs affecting serotonin. Am J Forensic Med Pathol 21:370-374

122. Wiergowski M, Schetz D, Jankowski Z, Sumińska-Zuminska B, Sein JA (2015) Intoxication of female patient with generalised cancer in hospital-a case report. Przegl Lek 72:485-487

123. Hernandez AF, Montero MN, Pla A, Villanueva E (1995) Fatal moclobemide overdose or death caused by serotonin syndrome? J Forensic Sci 40:128-130

124. Solarino B, Rießelmann B, Buschmann CT, Tsokos M (2010) Multidrug poisoning involving nicotine and tramadol. Forensic Sci Int 194:e17-e19

125. Mannocchi G, Napoleoni F, Napoletano S, Pantano F, Santoni M, Tittarelli R et al (2013) Fatal self administration of tramadol and propofol: a case report. J Forensic Leg Med 20:715-719

126. Zhang S, Guan D, Wang L, Wang H, Zhang G, Zhao R et al (2011) The expression of GABA (A) receptor alpha1 and GABA (B) receptor 1 in medulla oblongata solitary nucleus and ambiguous nucleus in the cases of tramadol intoxication. Fa Yi Xue Za Zhi 27:401-404

127. Barbera N, Fisichella M, Bosco A, Indorato F, Spadaro G, Romano G (2013) A suicidal poisoning due to tramadol. A metabolic approach to death investigation. J Forensic Leg Med 20:555-558

128. Afshari R, Afshar R, Mégarbane B (2011) Tramadol overdose: review of the literature. Réanimation 20:436

129. Tobias JD (1997) Seizure after overdose of tramadol. South Med J 90:826-827

130. Raffa RB, Wu C, Stone DJ Jr, Borenstein MR, Codd EE, Coogan TP (2000) Determination of the adsorption of tramadol hydrochloride by activated charcoal in vitro and in vivo. J Pharmacol Toxicol Methods 43:205-210

131. Bianchetti M, Beutler A, Ferrier P (1988) Acute poisoning with a narcotic (tramadol) in an infant of five weeks. Helv Paediatr Acta 43:241-244

132. Riedel F, von Stockhausen H-B (1984) Severe cerebral depression after intoxication with tramadol in a 6-month-old infant. Eur J Clin Pharmacol 26:631-632 
133. Lagard C, Malissin I, Indja W, Risède P, Chevillard L, Mégarbane $B$ (2017) Is naloxone the best antidote to reverse tramadolinduced neuro-respiratory toxicity in overdose? An experimental investigation in the rat. Clin Toxicol 56(8):737-743

134. Saidi H, Ghadiri M, Abbasi S, Ahmadi S-F (2010) Efficacy and safety of naloxone in the management of postseizure complaints of tramadol intoxicated patients: a self-controlled study. Emerg Med J 27:928-930

135. Vahabzadeh M, Moshiri M, Mohammadpour AH, Hosseinzadeh H (2013) Promising effects of intravenous lipid emulsion as an antidote in acute tramadol poisoning. Reg Anesth Pain Med $38: 425-430$

136. Abbasi B, Hafezimoghadam P, Ansari Nejad N, Sarvari M, Ramim T (2015) Assessment of time interval between tramadol intake and seizure and second drug-induced attack. Tehran Univ Med J 73:592-599

137. Mood NE, Sabzghabaee AM, Safdari A, Yaraghi A (2011) Clinical signs, hospitalization duration and outcome of tramadol intoxication. J Isfahan Med Sch 28

138. Farzaneh E, Samadzadeh M, Shahbazzadegan B, Sayadrezai I, Mostafazadeh B, Sarbandi Farahani A, et al (2012) Comparing the frequency of seizure in patients intoxicated with tramadol treated with or without naloxone. J Isfahan Med Sch 30

139. Ahmadimanesh M, Shadnia S, Rouini MR, Sheikholeslami B, Nasab SA, Ghazi-Khansari M (2018) Correlation between plasma concentrations of tramadol and its metabolites and the incidence of seizure in tramadol-intoxicated patients. Drug Metab Pers Ther 33:75-83

140. Ahmadi H, Hosseini J, Rezaei M (2008) Epidemiology of tramadol overdose in Imam Khomeini hospital, Kermanshah, Iran (2008). J Kermanshah Univ Med Sci 15

141. Murray BP, Carpenter JE, Dunkley CA, Moran TP, Alfaifi M, Alsukaiti WS et al (2019) Seizures in tramadol overdoses reported in the ToxIC registry: predisposing factors and the role of naloxone. Clin Toxicol 57(8):692-696

Publisher's Note Springer Nature remains neutral with regard to jurisdictional claims in published maps and institutional affiliations. 